\title{
Ethical implications of the perception and portrayal of dementia
}

\section{Debby Gerritsen, Jan Oyebode, Dianne Gove}

\begin{abstract}
The way we perceive and portray dementia has implications for how we act towards people with dementia and how we address the issue of dementia within society. As a multi-disciplinary working group, established within the framework of the European Dementia Ethics Network of Alzheimer Europe, we aimed to describe the different ways that people with dementia are perceived and portrayed within society and to consider the moral implications of this. In the current paper, we address perceptions of dementia as reflected in explanatory models of its cause and nature, descriptions of characteristics of people with dementia, the use of language, media portrayals and the views of people living with dementia. Academics and professionals could use this exploration to reflect on their behaviour and their use of language regarding people with dementia.
\end{abstract}

\section{About perceptions and the portrayal of dementia}

People make sense of dementia through the meanings and explanations they give to their personal observations, knowledge, beliefs, expectations and experiences, and through direct and indirect interaction with other people. The meanings and explanations we construct reflect complex processes of attending to some factors while disregarding others (Schacter, 2011). Hence, certain characteristics and ways of making sense of dementia become emphasised whilst others are given little or no attention. The way we perceive and portray dementia has implications for how we act towards people with dementia and how we address the issue of dementia within society, for example, in terms of care, treatment, social inclusion and human rights. As such, our perceptions and portrayals of dementia affect the lives of people with dementia. Since perceptions and portrayals prompt and/or permit actions that may be beneficial or harmful for people living with dementia, we 
view them as having moral implications, related to their consequences for what is accepted as right or wrong.

In 2009, Alzheimer Europe established the European Dementia Ethics Network with the aim of encouraging ethical reflection on topics of relevance to the lives of people with dementia and their carers. Within the framework of that Network, a multi-disciplinary working group, including also a person living with dementia and someone caring for a person with dementia, was formed in 2013. Our remit was to describe the different ways that people with dementia are perceived and portrayed within society and to consider the moral implications of this. On the basis of an extensive literature search, we explored the perceptions and portrayals of dementia of different groups of nonphilosophers in society, such as the general public, people with dementia, carers and healthcare professionals, and described these in a report (Alzheimer Europe, 2013). In the current paper, we address perceptions of dementia as reflected in explanatory models of its cause and nature, descriptions of characteristics of people with dementia, the use of language, media portrayals and the views of people living with dementia. We reflect on how various ways of perceiving and portraying dementia are likely to be beneficial or potentially harmful to people with dementia, with the aim to raise awareness and foster reflection about the possible implications for people living with dementia. This paper provides an iteration of material in the wider Alzheimer Europe report, presenting key aspects succinctly for an academic audience.

\section{Explanatory models of dementia}

People have been aware of dementia for as long as we have recorded history and many have tried to define and explain it. Disagreement over its cause and nature persists amongst lay people, professional carers, scientists and theorists. We identified several explanatory models and we briefly describe the possible ethical implications associated with each of these. We start with the three currently dominant perceptions of the nature and cause of dementia (Karenberg \& Forstl, 2006), 
namely dementia as a part of the normal ageing process, as a biomedical condition and as a mental disorder.

Although age is its strongest risk factor, dementia is not an inevitable part of ageing (Frölich, 2008). When people consider dementia as part of normal ageing (Ayalon \& Arean, 2004; Connell, Scott Roberts, \& McLaughlin, 2007; Corner \& Bond, 2004; Scodellaro \& Pin, 2013), they may delay or fail to consult a health care professional. Furthermore, age in itself often carries negative connotations, leading to ageist attitudes. Consequently, the belief that dementia is a natural part of ageing or affects only older people may contribute towards the stigmatisation of people with dementia on the basis of age (Chan \& Chan, 2009; Clarke, 2006; Iliffe et al., 2005).

When regarding dementia as a biomedical condition focussing on neuropathology (Cummings, 2007; Gaines \& Whitehouse, 2006), people may be motivated to seek diagnosis. However, a biomedical perspective may result in a focus on medical treatment and the quest for a cure, with the subsequent underdevelopment of appropriate social support for people with dementia and their carers (Swane, 1996). The focus of the biomedical model on damage to the brain may serve to distinguish dementia from (other) psychiatric conditions and from the normal ageing process, giving it a certain degree of "respectability" but, if taken to the extreme, risks reducing the person with dementia to "a damaged brain" and thus failing to respect personhood (Sabat, 2008). Failure to recognise the social aspects of dementia may result in the lack of comprehensive, coordinated care, particularly in countries where health care and social care are managed by separate bodies.

Regarding dementia as a mental disorder may increase stigma, since stigmatisation of people with psychiatric conditions or "mental health" problems is widespread (Angermeyer \& Matschinger, 2004; Corrigan, Kerr, \& Knudsen, 2005). On the other hand, not acknowledging the psychiatric aspects of dementia may deprive people of the expertise and psychiatric support provided by psychiatrists (Ngatcha-Ribert, 2004). 
Other explanatory models with developmental or biomedical connotations are dementia as a second childhood, as a hereditary or genetically determined condition, and as a contagious condition. Perceiving people with dementia as having returned to the state of a child (Jolley et al., 2009) may contribute towards attitudes and care practices which are demeaning, patronising, overprotective and disempowering, restricting rights and opportunities to exercise autonomy (Kitwood, 1997). Seeing dementia as a 'second childhood' could also be detrimental to dignity and wellbeing, positioning those with the condition as incapable and unable to take responsibility. It may undermine social roles and relationships, as the adult with dementia is perceived and treated as a wayward child (Jolley et al., 2009). Perceptions of dementia as a genetically determined medical condition (Lovestone, 2001) or contagious illness (Ayalon \& Arean, 2004); (Purandare, Luthra, Swarbrick, \& Burns, 2007) can be positive or negative, depending on people's understanding of genetics, probability and communicability which can vary considerably (Leibowitz, 1999). They may, for example contribute towards empathy, since members of the public can identify with what it may be like to carry a gene that increases vulnerability to a future illness, but equally may contribute towards fear and stigma, involving devaluation and social distancing.

In comparison to the above described explanatory models, bio-psycho-social (Kitwood, 1997) and disability (Gilleard, Higgs, Hyde, Wiggins, \& Blane, 2005) models focus less on specific group characteristics (e.g. old age or diagnostic criteria) and more on a holistic perspective of dementia. Both incorporate internal (e.g. individual personality traits, psychological and emotional aspects, biomedical factors) and external factors (e.g. relational factors and the environment) and imply a moral responsibility to provide holistic care that values identity. Bio-psycho-social perceptions of dementia and disability emphasise the importance of the person without rendering the person individually responsible for his/her condition. Bio-psycho-social perceptions may have an impact on the way that people with dementia are treated, as they acknowledge individuality and personhood. When translated into action they may foster an optimal level of functioning, thus contributing towards wellbeing, self-esteem and social integration (Kitwood, 1997). 
A final group of explanatory models focuses on causes related to spiritual and individual responsibility. In some cultural and ethnic groups, beliefs about dementia stemming from fate, evil spirits, the evil eye, lack of faith in or punishment from God are common (e.g. Blay \& Toledo Pisa Peluso, 2010; Downs, Small, \& Froggatt, 2006; Mackenzie, 2006; Uwakwe, 2000; Yeo, Horan, Jones, \& Pendleton, 2007). Further, perceiving dementia as resulting from inadequate personal characteristics such as laziness or sinfulness, or as being a consequence of poor personal self-care in relation to diet, exercise or life style (La Fontaine, Ahuja, Bradbury, Phillips, \& Oyebode, 2007; Low \& Anstey, 2009) may also increase blame and stigma. It seems possible that perceptions of blame towards those with dementia will increase as researchers discover more about lifestyle influences on the likelihood of developing dementia. The ethical principles related to these models touch on possible tensions between cultural sensitivity and health care responsibilities. For example, it is the ethical and professional duty of healthcare professionals to treat patients on the basis of the best current medical knowledge but healthcare professionals also have an ethical duty to behave responsibly with respect for people's individuality, values and beliefs. Consequently, an ethical dilemma may exist between providing the best evidence-based treatment and treating another's beliefs with respect. This calls for cultural sensitivity in health care professionals, focussing on people's individual belief systems (Iliffe \& Manthorpe, 2004).

To summarise, different models of the cause and nature of dementia have different moral implications. Most models potentially have both positive and negative moral implications, for instance with regard to equitable access to appropriate care and treatment, stigma, social inclusion or exclusion, dignity and personhood.

\section{The person with dementia}


Exploring views on personhood of people with dementia, we identified several perspectives: capacity-based perceptions, dualism, social death, and perceptions that focus on fundamental changes within the person.

A capacity-based view of personhood focuses on progressive loss of abilities, such as reasoning capacity, and memory, anticipating a loss of personhood at some point (Buchanan, 1988). This may result in the fundamental questioning of the human status of people with severe dementia. Dualism involves a perception of the body and the mind as two separate entities with one represented by something physical such as the brain and the other being detached from chemical or physiological processes, having a source and essence of its own (Hinshaw, 2007). Van Gorp and Vercruysse (Van Gorp \& Vercruysse, 2012) identified mind-body dualism as underpinning the most common conceptualisation regarding persons with dementia. A focus on dualism may result in considering a person with dementia as a living body without a mind. Furthermore, people with dementia may be viewed as experiencing a 'social death'. This is understood to mean that the person is considered "as good as dead" and is discounted in social terms (Sweeting \& Gilhooly, 1997). If, at any stage of the condition, people with dementia are not accorded the basic status of being fully human or their inherent or socially acquired personhood is not recognised, there is a risk of social exclusion and failure to respect their human dignity. Any perception that removes human status is unlikely to allow people with dementia to be treated with the same level of respect and care as that given to other people.

Related, though more subtly portrayed perceptions also imply fundamental changes within the person, such as becoming 'a different person' (Ngatcha-Ribert, 2004; Walters, Oyebode, \& Riley, 2010) or 'a stranger' (Basting, 2009; Wuest, Ericson, \& Stern, 1994; Walters et al., 2010), or 'losing their sense of self' (Sabat, 2008; McMillan, 2006). Seeing a person with dementia as having turned into a stranger carries implications for issues related to the provision of person-centred care. If the person is no longer perceived as the person who was previously known, then past relationships, by definition, cannot be retained, and the responsibility to provide person-centred care, which is built 
on a person's unique identity and personal history, may be discounted as no longer necessary.

Perceiving a person with dementia as having a fading or lost sense of self implies that the person with dementia exists in an amorphous state in which relationships lose meaning, and future oriented goals and hopes become futile. In contrast, within a person-centred care perspective, the focus remains on relating to the person with dementia as a unique individual and on his/her unique needs and wishes.

\section{Stereotypes of dementia}

Turning to the perceived characteristics of dementia, we find a few key stereotypes about how people are affected by dementia, what they look like and how they act.

A common stereotype is that consistent with severe dementia, including being in a nursing home and having a range of unpleasant, disturbing and far-reaching symptoms/deficits that are common in the later, but not earlier, stages of dementia (Alzheimer's Society, 2008; Ballenger, 2006; Gove, Downs, Vernooij-Dassen, \& Small, 2015; Sabat, 2008; Swane, 1996). Stereotypes of people with dementia being dangerous have also been reported (Blay \& Toledo Pisa Peluso, 2010; Swane, 1996), although several studies have recorded low scores for perceived dangerousness of people with Alzheimer's disease (Weiner, Perry, \& Magnusson, 1988; Werner, 2005; Werner \& Davidson, 2004; Werner \& Giveon, 2008). People with dementia are sometimes stereotyped as having no quality of life or capacity for pleasure, as being blissfully unaware, passive and having lost their control, identity and dignity (Corner \& Bond, 2004; Devlin, MacAskill, \& Stead, 2007). It has repeatedly been shown that carers perceive the quality of life of people with dementia as being lower than people with dementia perceive it themselves (e.g. Conde-Sala, Garre-Olmo, TurroGarriga, Lopez-Pousa, \& Vilalta-Franch, 2009; Crespo, Bernaldo de Quiros, Gomez, \& Hornillos, 2012). Images of people with dementia frequently reflect perceived lack of reciprocity, and communication with people with dementia is sometimes described in terms which emphasise it being one-sided, unrewarding, awkward and even embarrassing (Dunham \& Cannon, 2008; Gove, 
Small, Downs, \& Vernooij-Dassen, 2016; Graham \& Bassett, 2006). The perceived failure to give something back in the context of relationships has also been noted, but, as pointed out by VernooijDassen (Vernooij-Dassen, Leatherman, \& Olde Rikkert, 2011), reciprocity is often simply not recognised or older, frail people lack opportunities to reciprocate.

These stereotypes of people with dementia as vulnerable, dependent and as a potential burden, may contribute towards fear of dementia and of those who have it, as well as affecting the hope, self-esteem and sense of dignity of people living with the condition. Focusing on negative, disturbing and stereotypical images of dementia and ignoring ways in which people with dementia resemble other members of society may contribute towards an unrealistic fear of dementia and interfere with authentic communication with people with dementia. This may increase stigmatization and be damaging to existing and potential relationships between people with dementia and others. The perception of people with dementia as a group rather than as individuals with varying characteristics, abilities, levels, risks and types of vulnerability, dependency and care needs is problematic. A group-based approach increases the risk of a homogenised response and uniform task-focused treatment, overlooking similarities and differences amongst people with dementia and between them and other people. Thus, the challenge here may lie in acknowledging the diversity of people with dementia, interacting with them and reflecting on the numerous factors which influence how they are perceived, portrayed and subsequently treated.

\section{Words}

In addition to models of understanding and stereotypical perceptions, words and images themselves can have a powerful effect on the way that we think about (people with) dementia. George ( 2010) suggested we are faced with a moral challenge linked to semantic choice, whereby subtle alterations in the way that we talk about certain conditions may contribute to more sensitive approaches to them. This may, in turn, affect the way that people with dementia are treated within society. The words and metaphors that are used in connection with dementia are rich in symbolism and 
significance. They are sometimes used strategically to achieve certain goals, and sometimes used without forethought. However, there are very few expressions which can be considered as wholly "good" or "bad". For one person a word or metaphor (for example dementia as a journey or fight, or the person with dementia as "just a body" or "away with the fairies") might represent hope or help them to cope, whereas for another it sums up dread and loss of the self. Some words and metaphors are liberally used and paint a biased picture of dementia, whilst others are considered demeaning, depersonalising and insulting and are avoided. Over time, the use of words changes to avoid the negative connotations that develop from association with a condition that is still negatively valued; for example, "senility" being replaced by "dementia". Just as each term carries an ethical dimension, so each change can bring and foster a fresh perspective. For example, being labelled 'a dement' marries the person with the term and removes personhood; 'being demented' implies that a person with dementia is only this; "living with dementia" implies that one can still have a life with dementia, which in this phrase is separated from the self. Even standard medical terms, such as "dementia" or "Alzheimer's disease", are sometimes used with great caution due to an awareness of the possible impact on people's lives and wellbeing (Cahill et al., 2008; Gove et al., 2015; Robinson et al., 2008). Where there is fear of naming dementia due to its negative connotations, euphemisms may be coined which in themselves carry ethical dimensions. For example, the description of services as "memory clinics" may allow some to attend without a sense of stigma but may also deter those with different early symptoms from seeking help. Words clearly matter. They describe, communicate and reinforce our current perceptions of dementia. With awareness, we can try to use them positively to challenge portrayals of dementia and promote a more positive image of dementia and people with dementia.

\section{Portrayal in the media}


The media present messages and information about dementia which we may actively attend to, for example by watching a documentary or reading an article, or take in more vicariously, for example when a secondary character in our favourite soap opera happens to have dementia. We examined how dementia is portrayed in the media with particular reference to the use of 'frames' and the issue of accuracy and sensationalism.

The media offer powerful tools to communicate information about health issues, having the capacity to create awareness and positively influence perceptions, beliefs and attitudes (Doyle et al., 2012). However, the same tools have been reported as portraying negative images of dementia, perpetuating stereotypes about ageing, and inciting fear and stigma (Clarke, 2006); (Kirkman, 2006). Film and media producers do not merely set out to provide an accurate description of dementia. They have an interest in obtaining a certain impact, in providing entertainment, suspense and dramatic effect. They allow themselves a certain artistic license, working within the framework of various film genres and positioning potential spectators. Van Gorp, Vercruysse and Van den Bulck (2012) suggest that the media uses "frames" to offer a certain perspective to audiences and the general public. Particular frames such as those with negative interpretations of reality, can be strategically challenged through the creation of counter frames, aimed at offering an alternative perspective which is more nuanced but also credible and comprehensible to the general public (Van Gorp et al., 2012). For example, common frames are personifications of dementia as "the invader", 'the monster' or 'the thief'. The 'invader' is often accompanied by fighting or defensive terminology ('we'll fight it' or 'we'll defeat it'). Its proposed counterframe is that of "the strange travelling companion". Drawing on studies into the way that dementia is portrayed in the media, Van Gorp and Vercruysse ( 2012) highlight that there is a focus on the terminal stage of dementia which becomes representative of the whole trajectory of dementia; that people speak on behalf of people with dementia who rarely have the opportunity to speak for themselves; and that the burden of dementia on the family is emphasised. The use of frames has moral implications as they can be deliberately used to increase the likelihood of dementia being perceived in a particular way. 
In the context of cinema films, the explicit portrayal of the clinical picture of dementia has been found to be fairly accurate but with an emphasis on cognitive symptoms, fluctuations of consciousness and disengaged behaviour (Gerritsen, Kuin, \& Nijboer, 2014) and a failure to portray people with dementia as active agents. Drawing on Post's (1995) description of hyper-cognitivism, Swinnen (2012) reflects on the possibility that films contribute towards maintaining the stigma of dementia and to people's perception of a dissolution of the self through their emphasis on cognitive difficulties (such as language and memory). In depicting a personal, inescapable tragedy, including in their relationships with other people, this may strengthen the objectification of people with dementia.

\section{Perceptions of people with dementia themselves}

Descriptions of dementia are often phrased in terms of loss, fear and the medical, economic and social challenges it entails. The perspectives of people with dementia provide an inside account of dementia which is much richer. In the last few decades a number of people with dementia have written about their experience (Bryden, 2005,2015; Boden, 1998; DeBaggio, 2002; Davis, 1989; McGowin, 1993), and have actively sought to communicate their experience and perceptions of dementia to wider society, for instance by speaking about their experience of dementia at conferences, more recently through being active in social media (see, for example, Wendy Mitchell's blog 'Which Me am I Today) and through national and European working groups of people with dementia (Alzheimer Europe, 2016).

Many people with dementia have participated in research to enable others to gain insight into their experience. Some of the earlier personal accounts of dementia portrayed dementia as a fairly painful experience and as involving a struggle against cognitive decline. However, people with dementia are increasingly providing a more nuanced and to some extent more positive outlook on dementia. Some people in the early stages are even quite indifferent towards it (Steeman, Godderis, Grypdonck, De Bal, \& Dierckx de Casterle, 2007). A small-scale qualitative study of eight older people with dementia 
found that the descriptions of the experience of dementia ranged from "not a big deal" to "hellish" (Hulko, 2009).

Indeed, contrary to the common perception that people with dementia have a low quality of life, people with dementia do not tend to rate their quality of life as poor. Cahill et al. (2004) found that of 88 people with mild to moderate dementia, $67 \%$ reported having a good quality of life. In part, this was linked to having a sense of being useful. Interestingly, Dröes et al. (2006) point out that being of use was not mentioned by carers as being relevant to quality of life and Gerritsen et al. (Gerritsen et al., 2007) found that professional carers only focused on it to a minor degree. The importance of feeling useful and being able to give something back runs counter to the common perception of people with dementia as being unable or unwilling to reciprocate, which was one of the frames identified by van Gorp et al. (2012). In her opening address to the members of the European Working Group of People with Dementia of Alzheimer Europe in 2012, Helga Rohra, who lives with dementia, highlighted the importance of reciprocity, stating that "people with dementia want to give something to the people around them, not only to take". Subsequent discussions within the group revealed the shared perception that having dementia did not take away the ability to contribute towards society and that the ability to do so was important for self-esteem and quality of life.

\section{Implications}

To encourage a morally acceptable perception of dementia in professionals, researchers and others, it is important that we reflect on and consider our behaviour and language regarding people with dementia. We need to ask ourselves what our work and our words say about the person with dementia and their personhood, consider whether we are respectful and nuanced, and whether our portrayals show a balanced picture. To stimulate such reflection, at the end of our report (2013) we included a set of guidelines or 'points for reflection'. These were the result of our group discussions, rather than being systematically generated or directly linked to the reviewed literature. Alzheimer 
Europe will be using the report (2013), especially its points for reflection, as the starting point to take forward development, through its European Working Group of People with Dementia, of guidelines on the perception and portrayal of dementia.

\section{Conclusion}

In this paper, we have presented a variety of perceptions and portrayals of dementia and reflected on their possible impact on people with dementia. The consequences of each particular way of perceiving or portraying dementia may be beneficial in some respects, and potentially harmful in others, in other words, they have moral dimensions. This can depend on the time, the situation or context, the people involved, what is at stake, personal factors and issues linked to the social, political, economic and cultural climate. We learn from each other and from experience with the result that what seems appropriate and normal today might seem outrageous in years to come. We can learn a great deal from reflection and experience, but it is important also to act in the constantly changing real world and in relation to real people with dementia. For this to be possible, we need to ensure that people with dementia remain an integral part of our social worlds and society and that they and their views are valued. In many countries, dementia-friendly communities and initiatives, as well as national dementia strategies, are being developed (Alzheimer Europe, 2013, Alzheimer Europe, 2015) and the general public is increasingly becoming aware of the personal experience, wishes and needs of people with dementia. In this process, attention to the implications of various perceptions and portrayals may be of added value to the general public and society at large.

\section{Acknowledgements}

The authors would like to thank Dr. Inge Mutsaerts and Professor Femi Oyebode for providing their expert opinion on our use of philosophical terminology. Furthermore, we thank the members of Alzheimer Europe's taskforce on ethical issues linked to the perception and portrayal of dementia for their work on the report on which this article was based: Ms Bénédicte Gombault, Dr Fabrice Gzil, Ms 
Jana Kasparkova, Ms Sirpa Pietikaïnen, Dr Christine Swane, Prof. Baldwin Van Gorp, Ms Aino

Valtanen, Rev. Richard Wallace and Dr Daphne Wallace.

\section{Funding Acknowledgement}

The taskforce's work arises from the 2013 Work Plan of Alzheimer Europe, which received funding from the European Union in the framework of the Health Programme.

\section{Declaration of Conflicting Interests}

The Authors declare that there is no conflict of interest.

\section{References}

Alzheimer Europe. (2013). The ethical issues linked to the perceptions and the portrayal of people with dementia: Alzheimer Europe. http://www.alzheimer-europe.org/Publications/ Alzheimer-Europe-Reports.

Alzheimer Europe. (2015). Dementia in Europe Yearbook 2015: Is Europe becoming more dementia friendly: Alzheimer Europe. http://www.alzheimer-europe.org/Publications/Dementia-inEurope-Yearbooks.

Alzheimer Europe (2016). EWGPWD: who we are. Alzheimer Europe. http://www.alzheimereurope.org/Alzheimer-Europe/Who-we-are/European-Working-Group-of-People-withDementia.

Alzheimer's Society. (2008). Dementia: out of the shadows: Alzheimer's Society.

Angermeyer, M. C., \& Matschinger, H. (2004). The stereotype of schizophrenia and its impact on discrimination against people with schizophrenia: results from a representative survey in Germany. Schizophr Bull, 30(4), 1049-1061.

Ayalon, L., \& Arean, P. A. (2004). Knowledge of Alzheimer's disease in four ethnic groups of older adults. Int J Geriatr Psychiatry, 19(1), 51-57. doi: 10.1002/gps.1037

Ballenger, J. F. (2006). Self, senility, and Alzheimer's disease in modern America: a history: John Hopkins.

Basting, A. D. (2009). Forget memory: The John Hopkins University Press.

Blay, S. L., \& Toledo Pisa Peluso, E. (2010). Public stigma: the community's tolerance of Alzheimer disease. Am J Geriatr Psychiatry, 18(2), 163-171. doi: 10.1097/JGP.0b013e3181bea900

Boden, C. (1998). Who will I be when I die? . Sydney, NSW, Australia: Harper Collins.

Bryden, C. (2005). Dancing with dementia. London: Jessica Kingsley Publishers.

Bryden, C. (2015). Before I Forget: How I Survived a Diagnosis of Younger-Onset Dementia. Australia: Penguin Books.

Buchanan, A. (1988). Advance directives and the personal identity problem. Philos Public Aff, 17(4), 277-302.

Cahill, S., Begley, E., Topo, P., Saarikalle, K., Macijauskiene, J., Budraitiene, A., Hagen, I., Holthe, T., Jones, K. (2004). 'I know where this is going and I know it won't go back': Hearing the individual's voice in dementia quality of life assessments. Dementia: The International Journal of Social Research and Practice, 3(3), pp. doi: 10.1177/1471301204045163 
Cahill, S., Clark, M., O'Connell, H., Lawlor, B., Coen, R. F., \& Walsh, C. (2008). The attitudes and practices of general practitioners regarding dementia diagnosis in Ireland. Int J Geriatr Psychiatry, 23(7), 663-669. doi: 10.1002/gps.1956

Chan, P. A., \& Chan, T. (2009). The impact of discrimination against older people with dementia and its impact on student nurses professional socialisation. Nurse Educ Pract, 9(4), 221-227. doi: 10.1016/j.nepr.2008.05.005

Clarke, J. N. (2006). The case of the missing person: Alzheimer's disease in mass print magazines 1991-2001. Health Communication, 19(3), 269-276. doi: DOI 10.1207/s15327027hc1903_9

Conde-Sala, J. L., Garre-Olmo, J., Turro-Garriga, O., Lopez-Pousa, S., \& Vilalta-Franch, J. (2009). Factors related to perceived quality of life in patients with Alzheimer's disease: the patient's perception compared with that of caregivers. Int J Geriatr Psychiatry, 24(6), 585-594. doi: 10.1002/gps.2161

Connell, C. M., Scott Roberts, J., \& McLaughlin, S. J. (2007). Public opinion about Alzheimer disease among blacks, hispanics, and whites: results from a national survey. Alzheimer Dis Assoc Disord, 21(3), 232-240. doi: 10.1097/WAD.0b013e3181461740

Corner, L., \& Bond, J. (2004). Being at risk of dementia: Fears and anxieties of older adults. J Aging Stud, .18(2), pp. doi: 10.1016/j.jaging.2004.01.007

Corrigan, P. W., Kerr, A., \& Knudsen, L. (2005). The stigma of mental illness: Explanatory models and methods for change. Applied \& Preventive Psychology, 11(3), 179-190. doi: 10.1016/j.appsy.2005.07.001

Crespo, M., Bernaldo de Quiros, M., Gomez, M. M., \& Hornillos, C. (2012). Quality of life of nursing home residents with dementia: a comparison of perspectives of residents, family, and staff. Gerontologist, 52(1), 56-65. doi: 10.1093/geront/gnr080

Davis, R. (1989). My journey into Alzheimer's disease. Bucks: Scripture Press.

DeBaggio, T. (2002). Losing my mind: an intimate look at life with Alzheimer's. New York: Free Press.

Devlin, E., MacAskill, S., \& Stead, M. (2007). 'We're still the same people': Developing a mass media campaign to raise awareness and challenge the stigma of dementia. International Journal of Nonprofit and Voluntary Sector Marketing, .12(1), pp. doi: 10.1002/nvsm.273

Downs, M., Small, N., \& Froggatt, K. (2006). Explanatory models of dementia: links to end-of-life care. Int J Palliat Nurs, 12(5), 209-213. doi: 10.12968/ijpn.2006.12.5.21173

Doyle, C. J., Dunt, D. R., Pirkis, J., Dare, A., Day, S., \& Wijesundara, B. S. (2012). Media reports on dementia: quality and type of messages in Australian media. Australas J Ageing, 31(2), 96101. doi: 10.1111/j.1741-6612.2011.00543.x

Droes, R.-M., Boelens-Van der Knoop, E. C. C., Bos, J., Meihuizen, L., Ettema, T. P., Gerritsen, D. L., . . Scholzel-Dorenbos, C. J. M. (2006). Quality of life in dementia in perspective. Dementia: The International Journal of Social Research and Practice, .5(4), pp. doi: $10.1177 / 1471301206069929$

Dunham, C. C., \& Cannon, J. H. (2008). "They're still in control enough to be in control": Paradox of power in dementia caregiving. J Aging Stud, 22(1), 45-53. doi: 10.1016/j.jaging.2007.02.003

Frölich, L. (2008). Risk factors and prevention. In Alzheimer Europe (Ed.), Dementia in Europe Yearbook (pp. 122-138): Alzheimer Europe.

Gaines, A. D., \& Whitehouse, P. J. (2006). Building a mystery: Alzheimer's disease, mild cognitive impairment, and beyond. Philosophy, Psychiatry, \& Psychology, .13(1), pp. doi: 10.1353/ppp.2006.0037

George, D. R. (2010). Overcoming the social death of dementia through language. Lancet, 376(9741), 586-587.

Gerritsen, D. L., Ettema, T. P., Boelens, E., Bos, J., Hoogeveen, F., de Lange, J., . . Droes, R. M. (2007). Quality of life in dementia: do professional caregivers focus on the significant domains? Am J Alzheimers Dis Other Demen, 22(3), 176-183. doi: 10.1177/1533317507299771

Gerritsen, D. L., Kuin, Y., \& Nijboer, J. (2014). Dementia in the movies: the clinical picture. Aging Ment Health, 18(3), 276-280. doi: 10.1080/13607863.2013.837150 
Gilleard, C., Higgs, P., Hyde, M., Wiggins, R., \& Blane, D. (2005). Class, cohort, and consumption: The British experience of the third age. Journals of Gerontology Series B-Psychological Sciences and Social Sciences, 60(6), S305-S310.

Gove, D., Downs, M., Vernooij-Dassen, M., \& Small, N. (2015). Stigma and GPs' perceptions of dementia. Aging Ment Health, 1-10. doi: 10.1080/13607863.2015.1015962

Gove, D., Small, N., Downs, M., \& Vernooij-Dassen, M. (2016). General practitioners' perceptions of the stigma of dementia and the role of reciprocity. Dementia (London). doi: $10.1177 / 1471301215625657$

Graham, J. E., \& Bassett, R. (2006). Reciprocal relations: The recognition and co-construction of caring with Alzheimer's disease. J Aging Stud, 20(4), 335-349. doi: 10.1016/j.jaging.2005.12.003

Hinshaw, S. P. (2007). The mark of shame : stigma of mental illness and an agenda for change. Oxford; New York: Oxford University Press.

Hulko, W. (2009). From 'not a big deal' to 'hellish': Experiences of older people with dementia. J Aging Stud, 23(3), 131-144. doi: 10.1016/j.jaging.2007.11.002

Iliffe, S., De Lepeleire, J., Van Hout, H., Kenny, G., Lewis, A., Vernooij-Dassen, M., \& Group, D. (2005). Understanding obstacles to the recognition of and response to dementia in different European countries: a modified focus group approach using multinational, multi-disciplinary expert groups. Aging Ment Health, 9(1), 1-6.

Iliffe, S., \& Manthorpe, J. (2004). The debate on ethnicity and dementia: from category fallacy to person-centred care? Aging Ment Health, 8(4), 283-292. doi: $10.1080 / 13607860410001709656$

Jolley, D., Moreland, N., Read, K., Kaur, H., Jutlla, K., \& Clark, M. (2009). The 'Twice a Child' projects: Learning about dementia and related disorders within the black and minority ethnic population of an English city and improving relevant services. Ethnicity and Inequalities in Health and Social Care, .2(4), pp. doi: 10.1108/17570980200900024

Karenberg, A., \& Forstl, H. (2006). Dementia in the Greco-Roman world. Journal of the Neurological Sciences, 244(1-2), 5-9. doi: 10.1016/j.jns.2005.12.004

Kirkman, A. M. (2006). Dementia in the news: the media coverage of Alzheimer's disease. Australas J Ageing, 25(2), 74-79. doi: 10.1111/j.1741-6612.2006.00153.x

Kitwood, T. M. (1997). Dementia reconsidered : the person comes first. Buckingham England ; Philadelphia: Open University Press.

La Fontaine, J., Ahuja, J., Bradbury, N. M., Phillips, S., \& Oyebode, J. R. (2007). Understanding dementia amongst people in minority ethnic and cultural groups. J Adv Nurs, 60(6), 605-614. doi: 10.1111/j.1365-2648.2007.04444.x

Leibowitz, R. (1999). Genetic testing without treatment: the value of knowledge for its own sake. Medical Ethics, 1(1), 4-5.

Lovestone, S., Gauthier, S. (2001). Management of dementia.: Martin Dunitz Ltd.

Low, L. F., \& Anstey, K. J. (2009). Dementia literacy: recognition and beliefs on dementia of the Australian public. Alzheimers Dement, 5(1), 43-49. doi: 10.1016/j.jalz.2008.03.011

Mackenzie, J. Stigma and dementia: East European and South Asian family carers negotiating stigma in the UK. Dementia, 5(2), 233-249.

McGowin, D. F. (1993). Living in the labyrinth: a personal journey through the maze of Alzheimer's: Elder Books.

McMillan, J. (2006). Identity, self, and dementia. In S. J. L. J.C. Hughes, S.R. Sabat (Ed.), Dementia: Mind, Meaning, and the Person: Oxford University Press.

Ngatcha-Ribert, L. (2004). [Alzheimer disease and society: an analysis of its social representation]. Psychol Neuropsychiatr Vieil, 2(1), 49-66.

Post, S. G. (1995). The moral challenge of Alzheimer disease: Ethical issues from diagnosing to dying, 2nd edition: John Hopkins University Press. 
Purandare, N., Luthra, V., Swarbrick, C., \& Burns, A. (2007). Knowledge of dementia among South Asian (Indian) older people in Manchester, UK. Int J Geriatr Psychiatry, 22(8), 777-781. doi: 10.1002/gps.1740

Robinson, A. L., Emden, C. G., Elder, J. A., Lea, E. J., Vickers, J. C., \& Turner, P. A. (2008). Multiple views reveal the complexity of dementia diagnosis. Australas J Ageing, 27(4), 183-188. doi: 10.1111/j.1741-6612.2008.00316.x

Sabat, S. R. (2008). A bio-psycho-social approach to dementia. In M. D. B. Bowers (Ed.), Excellence in dementia care: research in practice, (pp. 70-84): Open University Press.

Schacter D. L., T., D., Wegner, G. D. M. . (2011). Psychology, 2nd Ed. New York, NY Worth Publishers

Scodellaro, C., \& Pin, S. (2013). The ambiguous relationships between aging and Alzheimer's disease: a critical literature review. Dementia (London), 12(1), 137-151. doi: $10.1177 / 1471301211421230$

Steeman, E., Godderis, J., Grypdonck, M., De Bal, N., \& Dierckx de Casterle, B. (2007). Living with dementia from the perspective of older people: is it a positive story? Aging Ment Health, 11(2), 119-130. doi: 10.1080/13607860600963364

Swane, C. E. (1996). Everyday life with dementia: Images and experience in a cultural gerontological perspective.

Sweeting, H., \& Gilhooly, M. (1997). Dementia and the phenomenon of social death. Sociol Health IIIn, 19(1), 93-117.

Swinnen, A. (2012). "Everyone is Romeo and Juliet!" Staging dementia in Wellkamm to Verona by Suzanne Osten. J Aging Stud, 26(3), 309-318. doi: 10.1016/j.jaging.2012.01.006

Uwakwe, R. (2000). Knowledge of religious organizations about dementia and their role in care. Int J Geriatr Psychiatry, 15(12), 1152-1153.

Van Gorp, B., \& Vercruysse, T. (2012). Frames and counter-frames giving meaning to dementia: a framing analysis of media content. Soc Sci Med, 74(8), 1274-1281. doi: 10.1016/j.socscimed.2011.12.045

Van Gorp, B., Vercruysse, T., \& Van den Bulck, J. (2012). Toward a more nuanced perception of Alzheimer's disease: designing and testing a campaign advertisement. Am J Alzheimers Dis Other Demen, 27(6), 388-396. doi: 10.1177/1533317512454707

Vernooij-Dassen, M., Leatherman, S., \& Olde Rikkert, M. (2011). Quality of care in frail older people: the fragile balance between receiving and giving. $B M J, 342$, d403. doi: $10.1136 / \mathrm{bmj} . \mathrm{d} 403$

Walters, A. H., Oyebode, J. R., \& Riley, G. A. (2010). The dynamics of continuity and discontinuity for women caring for a spouse with dementia. Dementia: The International Journal of Social Research and Practice, .9(2), pp. doi: 10.1177/1471301209354027

Weiner, B., Perry, R. P., \& Magnusson, J. (1988). An Attributional Analysis of Reactions to Stigmas. Journal of Personality and Social Psychology, 55(5), 738-748. doi: Doi 10.1037/00223514.55.5.738

Werner, P. (2005). Social distance towards a person with Alzheimer's disease. Int J Geriatr Psychiatry, 20(2), 182-188. doi: 10.1002/gps.1268

Werner, P., \& Davidson, M. (2004). Emotional reactions of lay persons to someone with Alzheimer's disease. Int J Geriatr Psychiatry, 19(4), 391-397. doi: 10.1002/gps.1107

Werner, P., \& Giveon, S. M. (2008). Discriminatory behavior of family physicians toward a person with Alzheimer's disease. Int Psychogeriatr, 20(4), 824-839. doi: $10.1017 /$ S1041610208007060

Wuest, J., Ericson, P. K., \& Stern, P. N. (1994). Becoming strangers: the changing family caregiving relationship in Alzheimer's disease. J Adv Nurs, 20(3), 437-443.

Yeo, L. H., Horan, M. A., Jones, M., \& Pendleton, N. (2007). Perceptions of risk and prevention of dementia in the healthy elderly. Dement Geriatr Cogn Disord, 23(6), 368-371. doi: $10.1159 / 000101338$ 
